Published in final edited form as:

Neurocrit Care. 2018 February ; 28(1): 4-11. doi:10.1007/s12028-017-0387-6.

\title{
Neurologic Complications of Transplantation
}

\author{
Rajat Dhar, MD \\ Department of Neurology, Washington University in St. Louis School of Medicine
}

\begin{abstract}
Neurological disturbances including encephalopathy, seizures, and focal deficits complicate the course $10-30 \%$ of patients undergoing organ or stem cell transplantation. While much or this morbidity is multifactorial and often associated with extra-cerebral dysfunction (e.g. graft dysfunction, metabolic derangements), immunosuppressive drugs also contribute significantly. This can either be through direct toxicity (e.g. posterior reversible encephalopathy syndrome from calcineurin inhibitors such as tacrolimus in the acute post-operative period) or by facilitating opportunistic infections in the months after transplantation. Other neurologic syndromes such as akinetic mutism and osmotic demyelination may also occur. While much of this neurological dysfunction may be reversible if related to metabolic factors or drug toxicity (and the etiology if recognized and reversed), cases of multifocal cerebral infarction, hemorrhage, or infection may have poor outcomes. As transplant patients survive longer, delayed infections (such as progressive multifocal leukoencephalopathy) and post-transplant malignancies are increasingly reported.
\end{abstract}

\section{Keywords}

organ transplantation; stem cell transplantation; immunosuppressive agents; postoperative complications; posterior reversible encephalopathy syndrome

\section{Introduction}

Techniques in organ and stem cell transplantation have greatly advanced over the past decades, dramatically improving the survival and outlook for patients with end-stage organ failure and other life-threatening diseases. This has resulted in an increase in the numbers of even sicker patients undergoing these complex surgical procedures, involving significant hemodynamic, hematologic, and physiologic derangements followed by exposure to highdose immunosuppressive regimens. This complex milieu places transplant recipients at highrisk for a spectrum of neurologic complications both in the immediate post-transplant period and in a delayed fashion. Early complications tend to occur in those with concomitant organ or graft dysfunction as part of a complicated post-operative course but can also result from specific toxicity from the numerous medications they are exposed to. While many complications are seen after almost any type of transplant types (e.g. drug toxicity), others

Correspondence to: Rajat Dhar, MD, Associate Professor, Department of Neurology (Division of Neurocritical Care), 660 S Euclid Avenue, Campus Box 8111, Saint Louis, MO 63110, Tel: (314) 362-2999, dharr@wustl.edu.

Conflict of Interest: The author is a consultant for Mid-America Transplant, an Organ Procurement Organization and Member of the Executive Committee of the Organ Donation Research Consortium. 
are more common and idiosyncratic to certain transplants (e.g. central pontine myelinolysis after liver transplantation).

\section{Methods}

We searched PubMed using the MeSH terms, "organ transplantation/adverse effects" (or "hematopoietic stem cell transplantation/adverse effects") combined with the keywords: encephalopathy, seizures, neurologic. We prioritized cohort studies that prospectively ascertained complications over case reports or retrospective studies. We also prioritized contemporary studies published within the past ten years over older studies. We reviewed the reference lists of recent articles and reviews for further relevant citations. Additional focused searches were carried out for specific complications.

\section{Epidemiology}

The frequency of neurologic complications has been studied more thoroughly in the acute period after transplantation. This has predominantly been through retrospective ascertainment, meaning that the true incidence of both subtle and delayed complications is likely underestimated by such studies. Nonetheless, neurologic complications seem to occur after 10-30\% of organ transplants, with encephalopathy being the most common $[1,2]$.

Older studies found that seizures were frequent, but contemporary studies have demonstrated a reduced incidence, likely as a result of more careful initiation and titration of drug regimens [3]. A recent study of 134 adult liver transplant recipients involved serial prospective evaluations by a neurologist [4]. Central nervous system (CNS) complications occurred in $33 \%$ of cases, including a $6 \%$ rate of seizures. Most morbidity was transient, reversible, and associated with systemic toxic-metabolic derangements. As is expected, such complications were associated with low mortality compared to the less frequent group associated with structural CNS disorders (e.g. cerebrovascular events, infections) that carried a higher mortality rate. Rates of neurologic complications do appear higher after more complex procedures such as liver and lung transplants and lowest after kidney transplantation. Timing of complications can also inform the likely etiology: early complications such as encephalopathy and seizures tend to be related to drug toxicity (when high-doses are often used) or organ dysfunction and toxic-metabolic derangements, while opportunistic infections more often occur one to six months after transplant, when immunosuppression has reached its peak.

As operative techniques and drug regimens have been refined, frequency of acute complications may be decreasing, while more recipients are surviving for years and delayed complications are increasing in relative frequency (for example, post-transplant malignancies are emerging as a larger problem). Patient-related factors may place certain recipients at higher risk of complications; for example, those with alcoholic cirrhosis and/or pre-operative hepatic encephalopathy appear to have a higher rate of delirium and postoperative encephalopathy after liver transplant $[5,6]$. Those with recurrent organ failure undergoing a second transplant also appear to be a higher risk [4]. Although cerebral edema is a major source of morbidity in acute liver failure (ALF), successful liver transplantation can result in complete resolution of edema and gratifying neurological recovery if it is 
performed prior to herniation [5]. Nonetheless, in a study of 60 patients with ALF who underwent transplantation (most with severe pre-operative encephalopathy) presence of moderate-severe radiographic edema was associated with a higher post-operative complication rate [7]. Therapeutic hypothermia may be utilized as a bridge to transplantation in such severe cases [8].

Hematopoietic stem cell transplantation (HSCT) involves the delivery of allogenic or autologous stem cells after ablation of native bone marrow. Myeloablative conditioning regimens have typically involved a combination of cyclophosphamide and total-body irradiation but newer lower-intensity regimens are utilizing alemtuzumab (a monoclonal antibody that depletes $\mathrm{T}$ and $\mathrm{B}$ cells). These patients lack a functioning immune and hematopoietic system till engraftment of new stem cells occurs, making them extremely susceptible to infections and bleeding complications. Allogenic HSCT (especially for leukemias) involves longer-term immunosuppression and ongoing risk of graft-versus-host disease (GVHD) and is therefore associated with a higher rate of complications than allogenic HSCT [9-11]. Lower-intensity regiments may be associated with fewer neurologic complications, but adequate studies to address this are lacking.

\section{Clinical Syndromes}

\section{Encephalopathy}

The most common presentation of a neurologic disturbance is altered mental status (encephalopathy), encompassing states of delirium, lethargy and coma. Rates of encephalopathy as high as 30-40\% have been reported after liver, small bowel, and lung transplantation, reflecting the complexity of these procedures and the frequency of perioperative metabolic derangements. While systemic toxic-metabolic causes are the most common contributors to postoperative encephalopathy, multifocal CNS processes such as strokes and infections must also be considered.

Failure to awaken after surgery usually relates to a serious intraoperative event affecting the CNS. This can be diffuse cerebral ischemia (i.e. hypoxic-ischemic encephalopathy, HIE) related to hypotension (e.g. blood loss, cardiac arrhythmias / arrest) or hypoxia, which can usually be uncovered by review of the operative record. Immediate CT imaging may be unrevealing while MRI usually shows diffusion restriction in a cortical laminar, patchy, or sometimes subcortical pattern [12]. Graft failure can also result in encephalopathy, whether related to hypoxia after lung transplantation, hypotension or prolonged need by bypass after heart transplant, or hepatic or uremic encephalopathy. Diffuse or multifocal vascular insults can result from air emboli or atheroma during vascular manipulation [13]. CT may only reveal subtle hypodensities (or intracranial air) while MRI will usually show an embolic pattern of strokes. Occasionally reversible drug effects can mimic a neurological catastrophe; delayed clearance of anesthetic or neuromuscular blocking agents may occur with hepatic or renal dysfunction and lead to slow awakening or prolonged paralysis. Finally, non-convulsive seizures should be excluded as a cause of persistent coma after organ transplantation with EEG [14]. Unless associated with massive anoxic encephalopathy, seizures represent an important reversible cause of coma. 
Encephalopathy after transplantation can also occur later during the acute hospitalization. This may manifest as agitation, confusion, or hallucinations in a patient recovering on the transplant service [15]. While such delirium is frequently multifactorial, certain common threads emerge. Those with pre-operative risk factors such as history of hepatic encephalopathy or alcohol/drug abuse may be at greater risk [5,6]. Post-operative metabolic derangements (from uremia, hyponatremia, to hypercalcemia) also play an important role. Drug toxicity comprises perhaps the largest contributor to encephalopathy, specifically the polypharmacy of neurotoxic medications such patients are commonly exposed to. This ranges from effects of common sedative-hypnotics and narcotics used post-operatively to more specific transplant-related medications such as immunosuppressive agents (see later section on Drug Toxicity). A specific encephalopathy relating to renal allograft rejection has been observed (distinct from consequences of uremia), termed, rejection encephalopathy and postulated to occur secondary to cytokine release [16]. Encephalopathy related to toxic or metabolic causes usually reverses once the offending agent or abnormality has been identified and removed.

However, in approx. one-third, encephalopathy is due to a primary CNS insult such as infection, stroke (including hemorrhage) or osmotic demyelination syndrome (ODS), where the prognosis is more guarded. If patients do not improve with correction of recognized toxic-metabolic factors, then further testing for CNS insult should be performed (e.g. MRI to look for stroke, ODS, or other lesion, CSF testing for occult infection).

Osmotic demyelination syndromes encompass the classic central pontine myelinolysis (CPM) as well as extra-pontine regions of injury from osmotic myelin injury [17]. Patients with chronic liver disease often have chronic hyponatremia and then experience perioperative shifts in serum sodium around the time of transplantation. This may result in oligodendrocyte injury and myelin loss in vulnerable brain regions. Mental status may be preserved in some who present in a locked-in state, while others develop concomitant encephalopathy (which may be delayed days to weeks post-operatively). Incidence of CPM after liver transplantation is estimated at $1-2 \%$, although newer series report an incidence below 1\% [3,18-20]. A large contemporary but retrospective review found 11 cases among almost a thousand transplant recipients, including a significant proportion with extra-pontine involvement [21]. This study also demonstrated that those with ODS had larger perioperative sodium shifts (17 vs. $10 \mathrm{mEq} / 1$ in those without ODS). Although CPM was once either only discovered at autopsy or in those devastated with locked-in states, the spectrum is now considerably broader and prognosis not as dire with milder cases diagnosed by MRI [22].

Akinetic mutism may be seen where patients appear awake but do not speak fluently or move spontaneously [23]. This syndrome has been primarily attributed to calcineurin inhibitors (CNI, i.e. cyclosporine and tacrolimus) and is reversible on stopping these medications [24]. A similar clinical picture has been reported in amphotericin treatment of HSCT patients and can be seen with extrapyramidal involvement from ODS [25,26]. The monoclonal antibody OKT3 also appeared to trigger akinetic mutism in a heart transplant recipient, reversible once the drug was discontinued and CD3+ lymphocyte counts normalized [27]. Mutism has been reported in $1 \%$ of liver transplant recipients during the acute post-operative period (often in association with seizures) and has been attributed in 
most of those to CNI toxicity [23]. Any patient with rigidity and mutism should also be evaluated for neuroleptic malignant or serotonin syndromes, especially in concert with fever and elevated creatine kinase levels [28].

\section{Seizures}

Seizures have been reported in 5-10\% of transplant recipients, clustered mostly around the acute post-operative period [18]. They may occur in isolation or, more commonly, in association with encephalopathy and share many etiologic factors in common. Management and prognosis is again determined by whether seizures are due to a systemic and usually reversible derangement (e.g. hypoglycemia, sepsis, drug toxicity) or a structural CNS disorder. Although seizures associated with CNS lesions are more likely to be focal in origin, the focal features at seizure onset are often missed. CNI toxicity is the most common cause of seizures, where the ictal event is frequently preceded by behavioral or mental status changes. In fact, half of seizures in a heart transplant series were associated with CNI toxicity [29]. Drug levels may not be elevated but instead toxicity may occur with a rapid rise in levels [30-32]. The diagnosis instead may rest on: 1) excluding other etiologies; 2) neuroimaging; 3 ) normalization of encephalopathy and cessation of seizures after drug discontinuation. Status epilepticus (SE) is not a common manifestation of seizures in adult transplant recipients, but appears to be more common in pediatric series. In fact, more than two-thirds of seizures in a series of pediatric HSCT presented with SE and drug toxicity accounted for over half these seizures [33]. Occasionally myoclonic movements can occur transiently after emergence from anesthesia (especially with propofol) and can be mistaken for seizures [34]. EEG is useful for those not regaining normal mentation after an isolated seizure (to rule out persistent non-convulsive seizures) or to evaluate unexplained movements.

Transplant patients will not require prolonged anticonvulsant therapy in most cases, especially if a reversible etiology is found and corrected. Phenytoin is not optimal for most transplant patients; it has significant drug interactions, including induction of cyclosporine metabolism and a high level of protein binding (leading to variably higher free levels in these sick patients with low albumin) [35]. Metabolism may be further impaired in patients with hepatic dysfunction. Rapid administration of phenytoin can also result in arrhythmias and hypotension, accentuated in hemodynamically susceptible transplant patients. For all these reasons, there is a shift toward using newer anticonvulsants such as levetiracetam or lacosamide; both can be loaded intravenously, do not undergo hepatic metabolism, and lack major drug interactions. They can be discontinued once the period of acute risk has abated, unless a persistent CNS lesion is present.

\section{Drug Toxicity}

The first calcineurin inhibitor, cyclosporine, revolutionized organ transplantation by dramatically improving graft survival [36]. Tacrolimus (FK506) is now more frequently used due to lower rates of rejection and other complications [37,38]. Most patients also receive corticosteroids and mycophenolate mofetil (MMF). Induction agents such as OKT3, basiliximab, daclizumab, and thymoglobulin may be given immediately after transplantation to prevent acute rejection. Most of these agents have narrow therapeutic windows and 
potential for neurotoxicity (Table 1). CNIs remain the leading cause of drug-related neurotoxicity (including encephalopathy, seizures, and tremor) after transplantation. These drugs bind to immunophilins to inhibit the calcineurin-mediated calcium-dependent signaling pathways that activate T cells and IL-2 [39]. Calcineurin is also a mediator of neuronal function and drug toxicity is postulated to occur through dysregulation of the blood-brain barrier (BBB) and impaired vasoconstriction of blood vessels in the brain [40]. This disruption results in the formation of vasogenic edema, with a predilection for the posterior cerebral hemispheres, i.e. posterior reversible encephalopathy syndrome (PRES). This can manifest with a myriad of neurologic symptoms, ranging from headache, confusion, and visual disturbances, to seizures and coma. Some patients have subtle prodromal symptoms of toxicity such as paresthesias, insomnia, or tremor [41].

PRES associated with CNIs is similar to that seen with hypertension and other etiologies (although most patients with PRES after transplantation are normotensive, an exception being after renal transplantation who may develop delayed PRES with hypertension). It predominantly but not exclusively affects white matter and can also affect frontal regions, cerebellum, and the brainstem. With the increased use of MR imaging in those with neurological symptoms after transplantation, it is apparent that most cases of overt CNI toxicity are associated with radiologic findings of PRES [42]. The incidence of PRES was $0.5 \%$ in one study of 4222 solid organ transplant recipients compared to $1.6 \%$ in a study of HSCT $[42,43]$. These are likely underestimates as no prospective study has evaluated all potentially symptomatic patients with MRI; however, a prospective series in HSCT found PRES in 7\%, with most occurring within the first thirty days [44]. Other factors may also precipitate PRES in transplant recipients, including hypertension, sepsis, renal failure, and other medications such as rituximab [45].

Both ODS and PML (progressive multifocal leukoencephalopathy) cause white matter abnormalities in transplant recipients but usually be differentiated from PRES based on imaging and presentation. ODS occurs mainly in the acute period after liver transplantation and presents with predominant motor/bulbar abnormalities (although encephalopathy and coma have been reported). MRI shows involvement of the central pons (classically in a trident or bat-shaped pattern) but basal ganglia and external capsule white matter can also be affected (not typical in PRES). PML occurs in a more delayed fashion and while it affects subcortical white matter, it is more often asymmetric and multifocal.

If CNI toxicity is suspected, dose should be reduced or drug discontinued, if possible. Improvement in symptoms (typically within days) after such interventions is supportive of the diagnosis. CNI therapy can be cautiously reinstituted (if symptoms were mild) or a new agent (such as sirolimus or everolimus, which have not been associated with toxicity) can be substituted to avoid rare cases of PRES recurrence $[31,46]$. Radiographic finding may take a week or more to fully resolve [47].

Focal deficits after transplantation can have a number of causes. Both ischemic and hemorrhagic stroke can occur, especially after cardiac surgery or in the setting of coagulopathy (e.g. with HSCT-induced bone marrow ablation or with hepatic dysfunction). However, other disorders such as brain abscesses, drug toxicity (e.g. asymmetric PRES), or 
Todd's paresis after seizures can mimic stroke. Infectious processes can also cause stroke: for example, VZV infection can cause a cerebral vasculitis while CNS aspergillosis can cause vascular disruption and multiple hemorrhagic lesions. Hemorrhage can also occur in the setting of severe PRES [48]. Conversely, many strokes in this setting are multifocal (e.g. shower of emboli) and may present with nonspecific mental status changes rather than clear and abrupt focal deficits. Brain imaging is required to evaluate those with focal deficits or non-resolving encephalopathy after transplant, to exclude CNS lesions such as stroke or infection. One series of 384 heart transplant recipients found strokes in 7\% [49]; most of these were ischemic and were detected in the early post-operative period.

Neuromuscular syndromes may also be seen in transplant recipients. For example, entrapment neuropathies and plexopathies related to positioning or surgical manipulation can follow transplant surgeries (e.g. femoral neuropathy in $2 \%$ of renal transplants) [50]. Phrenic nerve injury can be seen after heart or lung transplantation and can impair respiratory mechanics and ventilator weaning [51]. Generalized weakness may be seen as a result of critical illness polyneuropathy and/or myopathy (exacerbated by corticosteroid exposure), described in 7\% of one liver transplant series [52]. Severe hypophosphatemia, hypokalemia, or hypermagnesemia can also results in diffuse weakness, and Guillain-Barre syndrome has been described after surgery or with viral reactivation. Inflammatory myopathies may occur more frequently after HSCT, sometimes in associated with GVHD [53]. Polymyositis has also been described with tacrolimus exposure [54].

GVHD after HSCT merits special mention as it may be associated with peculiar complications. It results from immune-mediated attack by donor leukocytes on recipient tissues and most commonly involves skin (incl. oral mucosa), intestinal tract, liver, and lungs. Bowel involvement in GVHD can induce thiamine deficiency and precipitate acute Wernicke's encephalopathy [55]. Inflammatory myopathies may occur [56], but CNS involvement is infrequent and controversial; a diagnosis of CNS GVHD should only be made after exclusion of other processes such as opportunistic infections [57]. Nonetheless, a few cases of CNS vasculitis or immune-mediated encephalitis related to GVHD have been described [58]. Supportive features include concurrent involvement of other organs and clear response to immunosuppressive treatment. MRI has shown white matter lesions similar to those seen in multiple sclerosis [59]. Rarely, brain biopsy may be necessary if infectious etiologies cannot be excluded by imaging or serologic/ CSF testing.

Idiopathic hyperammonemia is a rare but potentially fatal syndrome seen in HSCT recipients during the period of severe neutropenia [60]. It shares features with Reye syndrome, with lethargy often progressing to seizures and coma, in association with diffuse brain edema and elevated ammonia levels; liver enzymes are usually normal or mildly elevated. MRI may reveal signal abnormality in the insular and cingulate cortices [61]. Urea cycle defects should be excluded by measurement of urinary amino acids and orotic acid. Effective therapies are lacking but hemodialysis or sodium benzoate to trap ammonia have been attempted [62]. 


\section{CNS Infections}

Improvements in immunosuppression have prolonged graft and patient survival after transplantation. However, this has placed more survivors at risk for opportunistic infections (OI). A full discussion of CNS infections is beyond the scope of this review but has been reviewed elsewhere [63]. Risk appears proportional to degree of immunosuppressive exposure (placing heart and intestinal recipients at highest risk) and presentation may be subtle and less acute than in those with functioning immune systems. Fever may be mild and neck stiffness is often absent with subacute/chronic meningitis. Any patient with subacute onset of encephalopathy or even persistent headache in the months to years after transplant should be evaluated for CNS infections. Specifically, reactivation of latent infections may occur; there is increasing recognition that pathogens such as human herpesvirus 6 (HHV-6, commonly acquired in childhood as a cause of roseola, with exanthema subitum) may cause CNS infections after transplantation. HHV-6 reactivation produces an encephalitis with predilection for the temporal lobes and may present with mental status changes, hallucinations, and an amnestic syndrome [64]. MRI may show abnormality in the limbic cortices (similar to herpes simplex encephalitis) and diagnosis requires high clinical suspicion and PCR testing for the virus in CSF (as CSF pleocytosis may be mild or absent) [65]; treatment is with foscarnet. A complete review of other viral infections can be found elsewhere [66].

Patients are also at risk for transmission of infections from donor tissue, including viruses such as rabies, West Nile, and lymphocytic choriomeningitis virus (LCMV) [67]. For this reason, undiagnosed cases of encephalitis or suspicious brain lesions represent exclusionary factors for organ donation. Inadvertent transmission usually results in clusters of similar infections in those receiving organs from a single donor [68]. Immunosuppressed transplant recipients may develop progressive multifocal leukoencephalopathy (PML) due to reactivation of the JC polyomavirus. Infection of oligodendrocytes results in myelin loss, with multifocal, asymmetric white matter lesions seen on MRI. Symptoms usually begin a year or more after transplant and evolve over weeks to months, including cognitive and motor impairments. CSF analysis can detect JC virus by PCR, avoiding need for brain biopsy. While there are currently no established therapies, a reduction in immunosuppression is often attempted, along with a trial of cytosine arabinoside or cidofovir. Along the same time frame, patients may develop post-transplant lymphoproliferative disorders (PTLD). While primary involvement of the CNS is rare, in such cases tumor is more often parenchymal (as seen in HIV/AIDS patients), with multiple periventricular enhancing lesions. Presentation can be similar to PML and CSF cytology can be negative (although EBV PCR may be detected) [69].

\section{Immune Reconstitution Inflammatory Syndrome}

IRIS reflects an exaggerated immune response as pathogen- and iatrogenic immunosuppression is reversed, commonly with treatment of an OI and concomitant reduction in immunosuppressive medications. Inflammatory involvement of the nervous system is reflected in leptomeningeal enhancement and CSF pleocytosis; it can mimic recurrent or relapsed infection as it is more likely to occur in those with CNS infectious involvement. In a recent series of 89 patients with post-transplant cryptococcosis, 14\% 
developed IRIS [70]. A reduction in cryptococcal antigen titers suggests IRIS over recurrent infection. Treatment is with corticosteroids.

\section{Acknowledgments}

Funding: No funding was received for this manuscript.

\section{References}

1. Senzolo M, Marco S, Ferronato C, Cecilia F, Burra P, Patrizia B. Neurologic complications after solid organ transplantation. Transplant international : official journal of the European Society for Organ Transplantation. 2009; 22:269-78. [PubMed: 19076332]

2. Pustavoitau A, Bhardwaj A, Stevens R. Neurological complications of transplantation. J Intensive Care Med. 2011; 26:209-22. [PubMed: 21764765]

3. Vizzini G, Asaro M, Miraglia R, et al. Changing picture of central nervous system complications in liver transplant recipients. Liver transplantation : official publication of the American Association for the Study of Liver Diseases and the International Liver Transplantation Society. 2011; 17:127985.

4. Bernhardt M, Pflugrad H, Goldbecker A, et al. Central nervous system complications after liver transplantation: common but mostly transient phenomena. Liver transplantation : official publication of the American Association for the Study of Liver Diseases and the International Liver Transplantation Society. 2015; 21:224-32.

5. Dhar R, Young G, Marotta P. Perioperative neurological complications after liver transplantation are best predicted by pre-transplant hepatic encephalopathy. Neurocritical care. 2008; 8:253-8. [PubMed: 17928960]

6. Buis CI, Wiesner RH, Krom RaF, Kremers WK, Wijdicks EF. Acute confusional state following liver transplantation for alcoholic liver disease. Neurology. 2002; 59:601-5. [PubMed: 12196657]

7. Chan G, Taqi A, Marotta P, et al. Long-term outcomes of emergency liver transplantation for acute liver failure. Liver transplantation : official publication of the American Association for the Study of Liver Diseases and the International Liver Transplantation Society. 2009; 15:1696-702.

8. Rabinstein AA. Treatment of brain edema in acute liver failure. Curr Treat Options Neurol. 2010; 12:129-41. [PubMed: 20842576]

9. Graus F, Saiz A, Sierra J, et al. Neurologic complications of autologous and allogeneic bone marrow transplantation in patients with leukemia: a comparative study. Neurology. 1996; 46:1004-9. [PubMed: 8780080]

10. Denier C, Bourhis JH, Lacroix C, et al. Spectrum and prognosis of neurologic complications after hematopoietic transplantation. Neurology. 2006; 67:1990-7. [PubMed: 17159106]

11. de Brabander C, Cornelissen J, Smitt PA, Vecht CJ, van den Bent MJ. Increased incidence of neurological complications in patients receiving an allogenic bone marrow transplantation from alternative donors. J Neurol Neurosurg Psychiatry. 2000; 68:36-40. [PubMed: 10601399]

12. Muttikkal TJ, Wintermark M. MRI patterns of global hypoxic-ischemic injury in adults. J Neuroradiol. 2013; 40:164-71. [PubMed: 23433904]

13. Starzl TE, Schneck SA, Mazzoni G, et al. Acute neurological complications after liver transplantation with particular reference to intraoperative cerebral air embolus. Ann Surg. 1978; 187:236-40. [PubMed: 345984]

14. Junna MR, Rabinstein Aa. Tacrolimus induced leukoencephalopathy presenting with status epilepticus and prolonged coma. Journal of neurology, neurosurgery, and psychiatry. 2007; 78:1410-1.

15. Beresford TP. Neuropsychiatric complications of liver and other solid organ transplantation. Liver Transplant. 2001; 7:S36-S45.

16. Gross ML, Pearson RM, Kennedy J, Moorhead JF, Sweny P. Rejection encephalopathy. Lancet. $1982 ; 2: 1217$. 
17. King JD, Rosner MH. Osmotic demyelination syndrome. Am J Med Sci. 2010; 339:561-7. [PubMed: 20453633]

18. Bronster DJ, Emre S, Boccagni P, Sheiner Pa, Schwartz ME, Miller CM. Central nervous system complications in liver transplant recipients--incidence, timing, and long-term follow-up. Clinical transplantation. 2000; 14:1-7. [PubMed: 10693627]

19. Lewis MB, Howdle PD. Neurologic complications of liver transplantation in adults. Neurology. 2003; 61:1174-8. [PubMed: 14610116]

20. Kim JM, Jung KH, Lee ST, Chu K, Roh JK. Central nervous system complications after liver transplantation. J Clin Neurosci. 2015; 22:1355-9. [PubMed: 26100156]

21. Crivellin C, Cagnin A, Manara R, et al. Risk factors for central pontine and extrapontine myelinolysis after liver transplantation: a single-center study. Transplantation. 2015; 99:1257-64. [PubMed: 25427166]

22. Menger H, Jorg J. Outcome of central pontine and extrapontine myelinolysis $(n=44)$. J Neurol. 1999; 246:700-5. [PubMed: 10460448]

23. Bronster DJ, Boccagni P, O’Rourke M, Emre S, Schwartz M, Miller C. Loss of speech after orthotopic liver transplantation. Transpl Int. 1995; 8:234-7. [PubMed: 7626186]

24. Sierra-Hidalgo F, Martinez-Salio A, Moreno-Garcia S, de Pablo-Fernandez E, Correas-Callero E, Ruiz-Morales J. Akinetic mutism induced by tacrolimus. Clin Neuropharmacol. 2009; 32:293-4. [PubMed: 19820432]

25. Laureno R, Karp BP. Cyclosporine mutism. Neurology. 1997; 48:296-7. [PubMed: 9008554]

26. Devinsky O, Lemann W, Evans AC, Moeller JR, Rottenberg DA. Akinetic mutism in a bone marrow transplant recipient following total-body irradiation and amphotericin $\mathrm{B}$ chemoprophylaxis. A positron emission tomographic and neuropathologic study. Arch Neurol. 1987; 44:414-7. [PubMed: 3548667]

27. Pittock SJ, Rabinstein AA, Edwards BS, Wijdicks EF. OKT3 neurotoxicity presenting as akinetic mutism. Transplantation. 2003; 75:1058-60. [PubMed: 12698102]

28. Garrido SM, Chauncey TR. Neuroleptic malignant syndrome following autologous peripheral blood stem cell transplantation. Bone Marrow Transplant. 1998; 21:427-8. [PubMed: 9509981]

29. Navarro V, Varnous S, Galanaud D, et al. Incidence and risk factors for seizures after heart transplantation. Journal of neurology. 2010; 257:563-8. [PubMed: 19894074]

30. Lane RJ, Roche SW, Leung AA, Greco A, Lange LS. Cyclosporin neurotoxicity in cardiac transplant recipients. J Neurol Neurosurg Psychiatry. 1988; 51:1434-7. [PubMed: 3069960]

31. Wijdicks EF, Wiesner RH, Krom RA. Neurotoxicity in liver transplant recipients with cyclosporine immunosuppression. Neurology. 1995; 45:1962-4. [PubMed: 7501141]

32. Wijdicks EF, Plevak DJ, Wiesner RH, Steers JL. Causes and outcome of seizures in liver transplant recipients. Neurology. 1996; 47:1523-5. [PubMed: 8960738]

33. Cordelli DM, Masetti R, Zama D, et al. Etiology, characteristics and outcome of seizures after pediatric hematopoietic stem cell transplantation. Seizure. 2014; 23:140-5. [PubMed: 24287078]

34. Walder B, Tramer MR, Seeck M. Seizure-like phenomena and propofol: a systematic review. Neurology. 2002; 58:1327-32. [PubMed: 12017156]

35. Keown PA, Laupacis A, Carruthers G, et al. Interaction between phenytoin and cyclosporine following organ transplantation. Transplantation. 1984; 38:304-6. [PubMed: 6474556]

36. Calne RY, White DJ, Thiru S, et al. Cyclosporin A in patients receiving renal allografts from cadaver donors. Lancet. 1978; 2:1323-7. [PubMed: 82836]

37. Webster A, Woodroffe RC, Taylor RS, Chapman JR, Craig JC. Tacrolimus versus cyclosporin as primary immunosuppression for kidney transplant recipients. Cochrane Database Syst Rev. 2005:CD003961. [PubMed: 16235347]

38. Hachem RR, Yusen RD, Chakinala MM, et al. A randomized controlled trial of tacrolimus versus cyclosporine after lung transplantation. J Heart Lung Transplant. 2007; 26:1012-8. [PubMed: 17919621]

39. Ho S, Clipstone N, Timmermann L, et al. The mechanism of action of cyclosporin A and FK506. Clin Immunol Immunopathol. 1996; 80:S40-5. [PubMed: 8811062] 
40. Dawson TM. Immunosuppressants, immunophilins, and the nervous system. Ann Neurol. 1996; 40:559-60. [PubMed: 8871573]

41. Bechstein WO. Neurotoxicity of calcineurin inhibitors: impact and clinical management. Transplant international : official journal of the European Society for Organ Transplantation. 2000; 13:313-26. [PubMed: 11052266]

42. Bartynski WS, Tan HP, Boardman JF, Shapiro R, Marsh JW. Posterior reversible encephalopathy syndrome after solid organ transplantation. AJNR American journal of neuroradiology. 2008; 29:924-30. [PubMed: 18272559]

43. Wong R, Beguelin GZ, de Lima M, et al. Tacrolimus-associated posterior reversible encephalopathy syndrome after allogeneic haematopoietic stem cell transplantation. Br J Haematol. 2003; 122:128-34. [PubMed: 12823354]

44. Siegal D, Keller A, Xu W, et al. Central nervous system complications after allogeneic hematopoietic stem cell transplantation: incidence, manifestations, and clinical significance. Biol Blood Marrow Transplant. 2007; 13:1369-79. [PubMed: 17950923]

45. Jaiswal A, Sabnani I, Baran DA, Zucker MJ. A unique case of rituximab-related posterior reversible encephalopathy syndrome in a heart transplant recipient with posttransplant lymphoproliferative disorder. Am J Transplant. 2015; 15:823-6. [PubMed: 25648447]

46. van de Beek D, Kremers WK, Kushwaha SS, McGregor CG, Wijdicks EF. No major neurologic complications with sirolimus use in heart transplant recipients. Mayo Clin Proc. 2009; 84:330-2. [PubMed: 19339650]

47. Singh N, Bonham A, Fukui M. Immunosuppressive-associated leukoencephalopathy in organ transplant recipients. Transplantation. 2000; 69:467-72. [PubMed: 10708096]

48. Lee VH, Wijdicks EF, Manno EM, Rabinstein AA. Clinical spectrum of reversible posterior leukoencephalopathy syndrome. Arch Neurol. 2008; 65:205-10. [PubMed: 18268188]

49. Munoz P, Valerio M, Palomo J, et al. Infectious and non-infectious neurologic complications in heart transplant recipients. Medicine (Baltimore). 2010; 89:166-75. [PubMed: 20453603]

50. Sharma KR, Cross J, Santiago F, Ayyar DR, Burke G 3rd. Incidence of acute femoral neuropathy following renal transplantation. Arch Neurol. 2002; 59:541-5. [PubMed: 11939888]

51. Maziak DE, Maurer JR, Kesten S. Diaphragmatic paralysis: a complication of lung transplantation. Ann Thorac Surg. 1996; 61:170-3. [PubMed: 8561547]

52. Campellone JV, Lacomis D, Kramer DJ, Van Cott AC, Giuliani MJ. Acute myopathy after liver transplantation. Neurology. 1998; 50:46-53. [PubMed: 9443456]

53. Ruzhansky KM, Brannagan TH 3rd. Neuromuscular complications of hematopoietic stem cell transplantation. Muscle Nerve. 2015; 52:480-7. [PubMed: 26044357]

54. Vattemi G, Marini M, Di Chio M, Colpani M, Guglielmi V, Tomelleri G. Polymyositis in solid organ transplant recipients receiving tacrolimus. J Neurol Sci. 2014; 345:239-43. [PubMed: 25130930]

55. Choi YJ, Park SJ, Kim JS, Kang EJ, Choi CW, Kim BS. Wernicke's encephalopathy following allogeneic hematopoietic stem cell transplantation. Korean J Hematol. 2010; 45:279-81. [PubMed: 21253432]

56. Stevens AM, Sullivan KM, Nelson JL. Polymyositis as a manifestation of chronic graft-versus-host disease. Rheumatology (Oxford). 2003; 42:34-9. [PubMed: 12509610]

57. Grauer O, Wolff D, Bertz H, et al. Neurological manifestations of chronic graft-versus-host disease after allogeneic haematopoietic stem cell transplantation: report from the Consensus Conference on Clinical Practice in chronic graft-versus-host disease. Brain. 2010; 133:2852-65. [PubMed: 20846944]

58. Sostak P, Padovan CS, Eigenbrod S, et al. Cerebral angiitis in four patients with chronic GVHD. Bone Marrow Transplant. 2010; 45:1181-8. [PubMed: 19915632]

59. Matsuo Y, Kamezaki K, Takeishi S, et al. Encephalomyelitis mimicking multiple sclerosis associated with chronic graft-versus-host disease after allogeneic bone marrow transplantation. Intern Med. 2009; 48:1453-6. [PubMed: 19687597]

60. Davies SM, Szabo E, Wagner JE, Ramsay NK, Weisdorf DJ. Idiopathic hyperammonemia: a frequently lethal complication of bone marrow transplantation. Bone Marrow Transplant. 1996; 17:1119-25. [PubMed: 8807124] 
61. Bindu PS, Sinha S, Taly AB, Christopher R, Kovoor JM. Cranial MRI in acute hyperammonemic encephalopathy. Pediatr Neurol. 2009; 41:139-42. [PubMed: 19589465]

62. del Rosario M, Werlin SL, Lauer SJ. Hyperammonemic encephalopathy after chemotherapy. Survival after treatment with sodium benzoate and sodium phenylacetate. J Clin Gastroenterol. 1997; 25:682-4. [PubMed: 9451687]

63. Fishman JA. Infection in solid-organ transplant recipients. N Engl J Med. 2007; 357:2601-14. [PubMed: 18094380]

64. Sadighi Z, Sabin ND, Hayden R, Stewart E, Pillai A. Diagnostic Clues to Human Herpesvirus 6 Encephalitis and Wernicke Encephalopathy After Pediatric Hematopoietic Cell Transplantation. J Child Neurol. 2015; 30:1307-14. [PubMed: 25564483]

65. Bhanushali MJ, Kranick SM, Freeman AF, et al. Human herpes 6 virus encephalitis complicating allogeneic hematopoietic stem cell transplantation. Neurology. 2013; 80:1494-500. [PubMed: 23516318]

66. Cukuranovic J, Ugrenovic S, Jovanovic I, Visnjic M, Stefanovic V. Viral infection in renal transplant recipients. ScientificWorldJournal. 2012; 2012:820621. [PubMed: 22654630]

67. Basavaraju SV, Kuehnert MJ, Zaki SR, Sejvar JJ. Encephalitis caused by pathogens transmitted through organ transplants, United States, 2002-2013. Emerg Infect Dis. 2014; 20:1443-51. [PubMed: 25148201]

68. Srinivasan A, Burton EC, Kuehnert MJ, et al. Transmission of rabies virus from an organ donor to four transplant recipients. N Engl J Med. 2005; 352:1103-11. [PubMed: 15784663]

69. Cavaliere R, Petroni G, Lopes MB, Schiff D. International Primary Central Nervous System Lymphoma Collaborative G. Primary central nervous system post-transplantation lymphoproliferative disorder: an International Primary Central Nervous System Lymphoma Collaborative Group Report. Cancer. 2010; 116:863-70. [PubMed: 20052713]

70. Sun HY, Alexander BD, Huprikar S, et al. Predictors of immune reconstitution syndrome in organ transplant recipients with cryptococcosis: implications for the management of immunosuppression. Clin Infect Dis. 2015; 60:36-44. [PubMed: 25210020] 
Table 1

Differential diagnosis of neurological symptoms and syndromes, including drug toxicity

\begin{tabular}{|c|c|c|}
\hline Symptom or Syndrome & Medications & Alternate Etiologies \\
\hline Headaches & $\begin{array}{l}\text { CNI, MMF, Sirolimus } \\
\text { OKT3 \& ATG (aseptic meningitis) }\end{array}$ & $\begin{array}{l}\text { Structural lesion } \\
\text { Opportunistic infection }\end{array}$ \\
\hline Tremor / Myoclonus & $\begin{array}{l}\text { CNI, Steroids, Sirolimus } \\
\text { Cephalosporins, ketamine }\end{array}$ & $\begin{array}{l}\text { ODS } \\
\text { Post-anoxic / HIE }\end{array}$ \\
\hline $\begin{array}{l}\text { Psychiatric disturbances (anxiety, } \\
\text { insomnia, hallucinations) }\end{array}$ & CNI, Steroids, MMF & Encephalitis (e.g. HHV-6) \\
\hline Encephalopathy, delirium & $\begin{array}{l}\text { CNI, OKT3, Steroids, Ganciclovir } \\
\text { May be multifactorial (consider concomitant } \\
\text { psychoactive meds) }\end{array}$ & $\begin{array}{l}\text { Organ / graft failure, Sepsis } \\
\text { Metabolic disturbances } \\
\text { Non-convulsive seizures } \\
\text { Multifocal or diffuse CNS lesions, ODS, OI } \\
\text { Wernicke encephalopathy }\end{array}$ \\
\hline Seizures & $\begin{array}{l}\text { CNI, Busulfan, OKT3 (rare), other medications } \\
\text { (imipenem, beta-lactams, metronidazole, theophylline) }\end{array}$ & $\begin{array}{l}\text { Hypoglycemia, metabolic } \\
\text { Structural brain lesion } \\
\text { Opportunistic infection }\end{array}$ \\
\hline Akinetic mutism & CNI, OKT3, amphotericin (with TBI) & $\begin{array}{l}\text { ODS } \\
\text { NMS }\end{array}$ \\
\hline PRES (white matter disease) & $\mathrm{CNI}$ & $\begin{array}{l}\text { PML, ODS } \\
\text { GVHD }\end{array}$ \\
\hline Paresthesias / neuropathy & $\begin{array}{l}\text { CNI, chemotherapy for HSCT, GVHD, thalidomide, } \\
\text { triazole antifungals }\end{array}$ & CMV reactivation \\
\hline Myopathy & Steroids & GVHD (polymyositis) \\
\hline Epidural lipomatosis & Steroids & \\
\hline
\end{tabular}

ATG = antithymocyte globulin; $\mathrm{CIP}=$ critical illness polyneuropathy CMV = cytomegalovirus CNI = calcineurin inhibitors; GVHD = graftversus-host disease; HIE = hypoxic-ischemic encephalopathy; HHV-6 = human herpesvirus 6; MMF = mycophenolate mofetil; NMS = neuroleptic malignant syndrome; ODS = osmotic demyelination syndrome; OI = opportunistic infections; $\mathrm{PML}=$ progressive multifocal leukoencephalopathy; TBI = total body irradiation 